\title{
Sexually transmitted infections in the military environment
}

\author{
Krzysztof Korzeniewski $^{1,2}$, Dariusz Juszczak ${ }^{3}$, Przemysław Paul ${ }^{2}$ \\ ${ }^{1}$ Department of Epidemiology and Tropical Medicine, Military Institute of Medicine, Warsaw, Poland \\ ${ }^{2}$ Department of Occupational, Metabolic and Internal Diseases, Institute of Maritime and Tropical Medicine, \\ Medical University of Gdansk, Poland \\ $37^{\text {th }}$ Navy Hospital, Gdansk, Poland
}

\begin{abstract}
Sexually transmitted infections (STIS) have always been a major health issue affecting military personnel in all types of services and in all armed forces around the world, especially during deployments and in operational settings. Although the research shows that STIs are still reported in the military, the epidemiological risk for contracting a sexually transmitted infection is much lower nowadays than it was in the past. It is important, however, that service members are routinely screened for sexually transmitted diseases. Because of a high prevalence of STIs in the general population as well as the asymptomatic nature of some infections (e.g. HIV, Chlamydia trachomatis), screening of the sexually active service personnel is recommended as a practical method of preventing the spread of STIs and their sequelae, such as pelvic inflammatory disease, ectopic pregnancy, infertility in women or epididymitis, prostatitis, infertility in men. The rates of STIs in service members have been on the increase in recent years, which may be associated with the fact that more and more women are now seeking a career in the armed forces. Currently, STIs do not only affect male soldiers or their civilian sexual partners (either long-term or casual), but both male and female soldiers alike, especially if they are serving together. The article focuses on the prevalence of STIs in the military in the past and at present, the common STI risk factors and prevention measures.
\end{abstract}

(Int Marit Health 2020; 71, 3: 207-212)

Key words: sexually transmitted infections, soldiers, epidemiology, risk factors, prevention

\section{INTRODUCTION}

Sexually transmitted infections (STIs) have always been a major health issue affecting military personnel all over the world, especially during deployments or in operational settings [1-3]. In the past commercial sex services were easily available wherever the troops were deployed and service members, mostly young and sexually active men, were often using the services offered by commercial sex workers (CSWs). In general, the history of STIs in the military can be organized into four major stages. During the first stage, which lasted until the early $20^{\text {th }}$ century, STIs were widespread in all armies and although they had a significant impact on individual as well as unit readiness, they were widely ignored by army officials. The second stage, lasting until 1940s, was a period of spectacular scientific advance, also in the field of laboratory diagnostics, which allowed for the identification of the common sexually transmitted pathogens. Once the etiological factors responsible for STIs were discovered, it was possible to limit transmission in the armed forces by implementing appropriate disease prevention measures. The third stage in the history of STIs began a few years later, when penicillin started to be mass-produced and used to treat gonorrhea and syphilis. The last stage, which lasts until today, started in the early 1980 s when laboratory tests for viral (HIV, HSV, HPV) as well as bacterial STIs (Chlamydia trachomatis and Neisseria gonorrhoeae) became more widespread [4-7]. STIs, especially those which are asymptomatic, like HIV or Chlamydia trachomatis infection, pose a serious epidemiological risk in closed communities, such as the military. Therefore, regular

Prof. Krzysztof Korzeniewski, MD, PhD, Chairman of the Polish Society of Maritime, Tropical and Travel Medicine, Powstania Styczniowego St. 9B, 81-519 Gdynia, Poland; Military Institute of Medicine, Head of the Department of Epidemiology and Tropical Medicine, Szaserów St. 128, 04-141 Warszawa, Poland, e-mail: kkorzeniewski@wim.mil.pl 
screening of the sexually active service men and women should become a priority for the military officials. Over the last 30 years, more and more women have been seeking a career in the armies of many NATO member states. In the late 1990s, women accounted for $17 \%$ of all new recruits in the United States (US) Forces [8]. STI screening of new female Army recruits has demonstrated a prevalence of more than $9 \%$ in a cohort of $>13,000$ women. The results have clearly shown that STIs do not only affect male military personnel or their civilian sexual partners (either long-term or casual) but male and female soldiers alike, especially if they are serving together [5]. The US Military Health Service has created and maintained an excellent system for the surveillance of communicable diseases and STIs. Thanks to the system, the US troops consisting of approximately 1.5 million personnel are the best diagnosed and medically consulted professional group in the US. According to the available data from the US military health service, the prevalence of STIs in the military personnel serving in the United States of America (USA) is similar to infection rates reported in the general American population. In operational settings, however, the epidemiological situation as regards the prevalence of STIs can change dramatically, especially if soldiers are deployed on operations to areas where STIs are more widespread [9].

\section{EPIDEMIOLOGY OF STIS IN THE MILITARY}

Sexually transmitted infections, mostly syphilis and gonorrhea, were the second most common factor affecting individual and unit readiness during World War I (the major factor was the 1918 flu pandemic) [2]. During World War II, the prevalence rates of STIs in the United States service personnel were estimated at 43/1000 soldiers. Soon after the war ended in Europe (May 1945) the prevalence of STIs (mainly gonorrhea) in American service members who were stationing in Germany reached the level of 190 cases/1000 soldiers [10]. Later, during the Korean War, i.e. between 1951 and 1955, STI prevalence in the US Forces personnel was reported to be 184 cases/1000 soldiers (with gonorrhea accounting for over $70 \%$ of all STI cases); in some units of the US Forces, however, the prevalence of STIs was as high as 500 cases per 1000 person-years [11]. Exceptionally high rates of STIs were also reported during the Vietnam War. At the time, STIs were listed as the number one diagnosis in the US military health service monthly reports. Between 1963 and 1972, the prevalence rates of STIs in American service members deployed to South-East Asia were estimated at 260 cases per 1000 person-years, with gonorrhea being the top diagnosis (90\% of cases) [2]. During the Vietnam War, all services of the US Armed Forces reported markedly increased prevalence of STIs. A study which involved the crew of a US Navy aircraft carrier demonstrated an annual rate of gonorrhea at 582 cases/1000 soldiers and of non-gonococcal urethritis at 459/1000 [12]. Most of the study subjects included in the study contracted an STI on a leave in the port during anonymous sexual encounters with CSWs. The common STIs diagnosed in service members during the conflicts in Korea and Vietnam were both of cosmopolitan and tropical nature, e.g. during the Korean War chancroid was the leading STI diagnosis in many US Forces units [13], and in Vietnam it was the second most common diagnosis after gonorrhea [14].

Sexually transmitted infections are extremely common in South-East Asia and Sub-Saharan Africa regions. The troops deployed on military operations (e.g. as part of the United Nations [UN] Forces) to either of the two regions will therefore have a much higher risk of exposure to STIs, especially if they maintain sexual relations with the locals or engage in sexual behavior with CSW [15]. In a group of Dutch soldiers deployed on a mission to Cambodia 45\% reported sexual contacts with CSWs during their deployment [16]. The UN peacekeeping mission to Cambodia which was carried out in the early 1990s was of special interest to the military health services owing to a particularly high incidence of STIs among local CSWs. A study which involved 437 Cambodian CSWs demonstrated that over $40.5 \%$ were infected with HIV, 38.7\% with Chlamydia trachomatis or Neisseria gonorrhoeae, and 13.8\% with Treponema pallidum [17]. The lack of condom use or inconsistent use of condoms among Cambodian CSWs was the principle factor responsible for the increased risk of STI transmission. In a study of 140 female CSWs from Siem Reap consistent condom use with their clients was reported by $78 \%$ of the surveyed sex workers compared to only $20 \%$ with their non-paying partners [18]. A study which involved more than 700 Polish soldiers deployed on the UNTAC operation between 1992 and 1993 demonstrated the STI prevalence of 13\% (a total of 92 STI cases, including gonorrhea - 85 cases, HIV -5 cases and syphilis -1 case). All of the infected soldiers reported sexual contact with local women or CSWs. The younger, lower-ranking troops (mostly privates) were markedly more affected compared to other soldiers [19]. All Polish soldiers who were taking part in the UN mission in Cambodia ( $n=1254$ ) were screened for communicable diseases as well as STIs after they had returned to Poland. Ninety-seven of the soldiers were diagnosed with STIs. The cases included: HIV infections (9 cases, including 1 case of acquired immunodeficiency syndrome [AIDS]), gonorrhea (55 cases), syphilis (8 cases), genital warts (17), genital herpes (5), granuloma inguinale (2), lymphogranuloma venereum (1) [20]. Over the last 30 years, there has been a significant reduction in the number of STI cases on overseas operations in all NATO member armies (the estimates were primarily based on the US Forces medical data). As an 
example, the prevalence rate of STIs in the US service members during Operation Desert Storm (the Persian Gulf War) or Operation Restore Hope (Somalia) did not exceed $1 \%$. Such a drastic reduction in the number of STI cases was undoubtedly culture-specific as both operations took place in Muslim countries, where commercial sex services were not easily available. On operations to the Middle East or Central Asia, where the Islamic code of behavior is strictly enforced, the deployed military personnel have limited contact with the locals, especially with women, and are strongly discouraged from having any sexual relations with the local people or the local CSWs [21]. Although limiting sexual contacts with CSWs in operational settings resulted in the reduction of STI prevalence during the NATO-led operations and missions, sexually transmitted diseases remain a major health issue in the military, especially in the group of younger soldiers who are more likely to have sex with casual partners, both the military personnel and civilians. The results of the STI screening, which was conducted in the early 1990 s, showed that $7 \%$ of American service members aged under 25 were infected with gonorrhea and $15 \%$ had a chlamydial infection $[22,23]$. Further studies, carried out between 2004 and 2009, also demonstrated high prevalence of Chlamydia trachomatis infections in the US Forces personnel, particularly among young women (770/100,000 vs. men 192/100,000) [24]. High prevalence of STIs in young female soldiers led to the introduction of the Preventive Services Task Force guidelines. The guidelines recommend that all sexually active female soldiers under the age of 25 as well as all other soldiers over the age of 25 from high-risk groups should be screened for chlamydia and gonorrhea once every year [25]. Currently, Chlamydia trachomatis and Neisseria gonorrhoeae infections are the most prevalent of all STIs reported in the US Forces, with soldiers aged 17-24 being at the highest risk of transmission. Between 2006 and 2015, the mean prevalence of chlamydia and gonorrhea in active-duty personnel of the US Forces was reported to be $1.3 \%$ and $0.2 \%$, respectively [26]. Because of the asymptomatic nature of some STIs (e.g. Chlamydia infection is asymptomatic in nearly $90 \%$ of infected men and $70 \%$ of women), STI screening of the sexually active service personnel is recommended as a practical method of preventing the spread of STIs (both in the military and among civilians) and their sequelae such as pelvic inflammatory disease, ectopic pregnancy, infertility in women or epididymitis, prostatitis, infertility in men [27]. It has been estimated that chlamydia is the most common of all STIs in the US (both in the general population and in the military) [28]. The Defense Medical Surveillance System reports issued between 2000 and 2008 focusing on non-deployed American service personnel demonstrated an overall incidence of 922 cases of Chlamydia infections per 100,000 person-years $(392 / 100,000$ in the Navy; $1431 / 100,000$ in the Army); a total of 103,000 cases of chlamydia were reported within the period [29]. Gonorrhea, a disease caused by Neisseria gonorrhoeae, is the second most common STI in the US Forces service personnel. In the past the disease was a leading STI diagnosis and formed a point of reference for estimating morbidity rates in the military [3]. In 2003, the prevalence of gonorrhea in the US Forces was estimated at 143 cases/100,000 person compared to $116 / 100,000$ reported in the general population. Such high rates are mainly due to a large number of asymptomatic cases, especially in females. $N$. gonorrhoeae infections are asymptomatic in $50 \%$ of infected women and in $10 \%$ of infected men [28]. Since AIDS emerged in the 1980 s, the disease has become a major area of concern for the military medical services in terms of epidemiology (asymptomatic cases) and treatment (clinically severe cases, high mortality). As early as in1985, the US Forces officials introduced a HIV testing requirement for all military blood donors, recruits, active-duty soldiers, Reserve Soldiers and the National Guard [30]. Until the late 1990s, HIV incidence in the US service personnel remained at a relatively low level [31] and seroconversion was reported in 1275 of all the US service members [32]. In the following years, however, the number of cases began to rise. Until 2004, the US Air Force medical services reported 1373 HIV infections among their ranks; a total of 561 American soldiers died of AIDS [2]. Between 2011 and 2019, the US Forces personnel were screened for chlamydia, gonorrhea, HSV, HPV and syphilis. The prevalence rates were found to be 184.6, 28.4, 23.3, 56.4 and 4.3/10,000 person-years, respectively. The groups which exhibited higher STI rates included young females, Afro-Americans, US Army personnel, junior enlisted personnel (E1-E4) and poorly educated personnel [33]. Higher transmission rates are reported among military personnel assigned to a duty on the base. Screening of more than 1700 American troops preparing for their deployments to Iraq and Afghanistan in Camp Doha, Kuwait showed 44 cases of STIs, mostly genital herpes (HSV), genital warts (HPV) and chlamydia. It was estimated that the biggest risk of transmission on the base is from asymptomatic female soldiers [34]. According to the reports from the military medical services, the highest prevalence of STIs is seen among young recruits, whose unhealthy habits and high-risk behaviors are attributable to their background and education [35, 36]. Nearly $50 \%$ of all the STI cases reported in the USA are diagnosed in people aged 17-24 [37]. All applicants to the US Forces must undergo a thorough medical examination, including a compulsory HIV test, but they are not screened for any other sexually transmitted pathogens. Thus, it may be assumed that a large percentage of recruits entering the US Forces are infected 
with an STI of either viral of bacterial etiology [38, 39]. The Center for Disease Control and Prevention (CDC) estimates that there are several million new STIs in the USA each year [37]; nearly $50 \%$ of those cases are reported among young people who are generally more likely to engage in high-risk sexual behaviors such as anonymous sex encounter or sex without a condom. According to the CDC reports, the three most commonly reported STIs in the USA include chlamydia, gonorrhea and syphilis. In 2018, there were 1.8 million Chlamydia trachomatis infections (540/100,000), 583,000 Neisseria gonorrhoeae infections $(179 / 100,000)$ and 35,000 Treponema pallidum infections $(10 / 100,000)$ [40].

\section{RISK FACTORS AND STIS PREVENTION}

Military personnel are predominantly young, sexually active people who are more likely to engage in high-risk sexual behaviors than older people. The highest overall rates of STIs are seen in young, lower ranking enlisted personnel. On the other hand, higher-ranking, older and better educated service members have a much lower risk of contracting an STI because they are more likely to use condoms with casual partners [41]. STI screening of service men from the US Navy and Marine Corps ( $n=1744$; mean age 23 years) during their deployment to South America and Africa demonstrated the STI prevalence of $10 \%$, of which $90 \%$ was reported in enlisted personnel. More than $40 \%$ of the Navy or Marines personnel included in the study reported casual sex with CSWs during port calls [9]. The modes of transmission for STIs and other communicable diseases are obviously quite different. Although STIs do not affect the population as whole but rather sexually active individuals, STI surveillance and control remains problematic for a number of reasons. First of all, a majority of infections are transmitted from asymptomatic carriers or from people who often engage in casual sex with multiple partners [42]. Secondly, recovery from an STI does not confer lifelong immunity. And finally, non-specific clinical picture or co-infection with several different STIs may impede the diagnosis and treatment. In view of these facts, STI screening seems to be the most effective method of controlling the spread of STIs [43].

The most common risk factors for STIs, both in the military and among civilians, include sexual contacts with CSWs, sex with casual partners, sexual contacts with multiple partners, homosexual contacts, sexual contacts with partners injecting drugs and unprotected sexual contacts (lack of condom use). Other risk factors comprise early sexual initiation, lack of STI testing and avoiding medical treatment [44] as well as misuse of alcohol and use of drugs, having a history of STIs and lack of circumcision [41]. It is considered that substance misuse can inhibit judgment and affect soldiers' morale which in turn makes them more willing to engage in risky sexual behaviors [45]. A vast ma- jority of STIs that are reported in the military are diagnosed among the youngest troops who tend to have lower inhibitions and are more likely to engage in casual sex in order to relieve stress. It is not uncommon that younger soldiers are encouraged by their older colleagues to have sexual relations with CSWs as a good way of spending their time off-duty [41]. During the war in Vietnam, sexual relations with CSWs (many of whom were infected with at least one STI) were popular among soldiers of all ages - not only the younger and lower-ranking soldiers but also with the older and more experienced service members (regardless of their age, education or marital status). According to the surveys administered to the US Forces personnel who had taken part in the Vietnam War a total of $44 \%$ of married soldiers, $56 \%$ of soldiers $>30$ years and $30 \%$ of soldiers with a secondary school education considered sex with CSWs to be a natural way of spending their time off-duty [46]. Increased prevalence of STIs on overseas deployments may partly be attributable to a lack of entertainment or leisure facilities on the base, which makes soldiers look for different ways to prevent boredom and deal with stress. In terms of STI control, the primary objective of the military preventive medicine specialists is to identify the major risk factors, conduct screening tests and provide medical treatment. However, close cooperation with the local health service is just as important. For example, the cooperation between the US Navy medical services and the Department of Social Hygiene in the Philippines (regular STI screening of the local CSWs who reported sexual contacts with American service members and medical treatment of the local CSWs infected with a sexually transmitted disease) significantly reduced the number of STI cases among the American military personnel [47]. A study of the Polish Special Forces personnel identified yet other factors contributing to a lower STI incidence in operational settings. The study involved 253 service members, all sexually-active men and women, $44 \%$ of the subjects reported sexual contacts with more than one partner in the last 12 months. Screening test results showed that only two male soldiers ( $0.8 \%$ of the group) were infected with an STI (Chlamydia trachomatis). A majority of the study subjects reported consistent condom use when having casual sex or avoided casual sex because they were staying in a mutually monogamous relationship. The main reason for such self-imposed precautions was associated with the fear of getting infected with HIV and of the consequences of acquiring the infection [48].

\section{CONCLUSIONS}

From the epidemiological standpoint, sexually transmitted infections do not pose a serious health risk to the military personnel. It is, however, strongly recommended that service members are regularly screened for the most 
common STIs. Unprotected casual sex carries a high risk of STI transmission, especially in case of contacts with infected CSWs or with asymptomatic carriers (both groups being the major source of transmission). Because of the asymptomatic nature of some STIS, STI screening of the sexually active service personnel is recommended as a practical method of preventing the spread of sexually transmitted diseases. Over the recent years, the rates of STI cases have been rising in both male and female service members, which may be attributable to the fact that military service is no longer an all-male profession but is increasingly popular with women. Currently, women account for $15 \%$ of all military personnel in the US Forces. Sexual relations between male and female soldiers who are serving together have become commonplace. The results of routine screening of the US Forces personnel, the best diagnosed and medically consulted professional group in the US, have demonstrated that the introduction of routine STI screening for both men and women has become a necessity, especially before recruitment and prior to foreign deployment. The most common STIs reported in the military personnel include chlamydia, gonorrhea, syphilis and viral STIs (HSV, HPV, HIV); with Chlamydia trachomatis infection being the leading diagnosis, but the growing concern is about largely asymptomatic HIV and chlamydial infections. In order to limit transmission, mandatory HIV testing is regularly carried out in most armed forces around the world. The rates of STI cases are reported to rise in operational settings, especially in war zones. Military personnel are predominantly young, sexually active men who are likely to engage in casual sex in order to relieve stress. The rates of STI cases will much depend on the operational setting itself. On operations to the Middle East or Central Asia, where the Islamic code of behavior is strictly enforced, the deployed military personnel are strongly discouraged from having any sexual relations with the locals. For this reason, the risk of STI transmission on operations in the above mentioned regions is estimated to be low. However, the situation is quite different on operations to South-East Asia or Sub-Saharan Africa, where the deployed military personnel will have easy access to sexual services provided by CSWs, and because a significant proportion of the local CSWs are carriers of STIs. Hence, the risk of transmission will naturally be much higher than in the Middle East or Central Asia. The spread of STIs in operational settings can be effectively controlled through coordinated actions of the military health services deployed in the region, i.e. through epidemiological surveillance, effective elimination of risk factors and the introduction of appropriate preventive measures.

\section{REFERENCES}

1. Gaydos JC, McKee KT, Faix DJ. Sexually transmitted infections in the military: new challenges for an old problem. Sex Transm Infect. 2015; 91(8): 536-537, doi: 10.1136/sextrans-2015-052256, indexed in Pubmed: 26586846.
2. Rasnake MS, Conger NG, McAllister K, et al. History of U.S. military contributions to the study of sexually transmitted diseases. Mil Med. 2005; 170(4 Suppl): 61-65, doi: 10.7205/milmed.170.4s.61, indexed in Pubmed: 15916284.

3. Emerson L. Sexually transmitted disease control in the armed forces, past and present. Mil Med. 1997; 162(2): 87-91, doi: 10.1093/ milmed/162.2.87.

4. Gaydos CA, Quinn TC, Gaydos JC. The challenge of sexually transmitted diseases for the military: what has changed? Clin Infect Dis. 2000; 30(4): $719-722$, doi: $10.1086 / 313758$, indexed in Pubmed: 10770734.

5. Gaydos CA, Howell MR, Pare B, et al. Chlamydia trachomatis infections in female military recruits. N Engl J Med. 1998; 339(11): 739-744, doi: 10.1056/NEJM199809103391105, indexed in Pubmed: 9731090.

6. Fleming DT, McQuillan GM, Johnson RE, et al. Herpes simplex virus type 2 in the United States, 1976 to 1994. N Engl J Med. 1997; 337(16): 1105-1111, doi: 10.1056/NEJM199710163371601, indexed in Pubmed: 9329932.

7. Kotloff KL, Wasserman SS, Russ K, et al. Detection of genital human papillomavirus and associated cytological abnormalities among college women. Sex Transm Dis. 1998; 25(5): 243-250, doi: 10.1097/00007435199805000-00005, indexed in Pubmed: 9587175.

8. Walter Reed Army Institute of Research. Accession medical standards analysis and research activity. Annual report, Washington DC 1998.

9. Malone JD, Hyams KC, Hawkins RE, et al. Risk factors for sexually-transmitted diseases among deployed U.S. military personnel. Sex Transm Dis. 1993; 20(5): 294-298, doi: 10.1097/00007435199309000-00011, indexed in Pubmed: 8235929.

10. Sternberg HT, Howard E. Venereal diseases. In: Communicable Diseases Transmitted Through Contact or By Unknown Means. Vol. 5. In: Preventive Medicine in World War II . U.S. Department of the Army, Office of the Surgeon General, Washington DC 1960: 139.

11. McNinch JH. Venereal disease problems: U.S. Army Forces, Far East 1950-1953. Proceedings of Recent Advances in Medicine and Surgery, 19-30 April 1954. Army Medical Service Graduate School, Walter Reed Army Medical Center, Washington DC.

12. Harrison WO. Cohort study of venereal diseases, Proceedings of One-hundred - second Annual Meeting of the American Public Health Association and Related Organizations, New Orleans, USA 20-24 October 1974.

13. Asin J. Chancroid; a report of 1,402 cases. Am J Syph Gonorrhea Vener Dis. 1952; 36(5): 483-487, indexed in Pubmed: 14952691.

14. Kerber RE, Rowe CE, Gilbert KR. Treatment of chancroid. A comparison of tetracycline and sulfisoxazole. Arch Dermatol. 1969; 100(5): 604-607, indexed in Pubmed: 5350417.

15. Soeprapto W, Ertono S, Hudoyo H, et al. HIV and peacekeeping operations in Cambodia. Lancet. 1995; 346(8985): 1304-1305, doi: 10.1016/s0140-6736(95)91910-4, indexed in Pubmed: 7475754.

16. Hopperus Buma AP, Veltink RL, van Ameijden EJ, et al. Sexual behaviour and sexually transmitted diseases in Dutch marines and naval personnel on a United Nations mission in Cambodia. Genitourin Med. 1995; 71(3): 172-175, doi: 10.1136/sti.71.3.172, indexed in Pubmed: 7635494.

17. Ryan C, Vathiny O, Gorbach P, et al. Explosive spread of HIV-1 and sexually transmitted diseases in Cambodia. Lancet. 1998; 351(9110): 1175, doi: 10.1016/s0140-6736(98)24016-5.

18. Wong ML, Lubek I, Dy BC, et al. Social and behavioural factors associated with condom use among direct sex workers in Siem Reap, Cambodia. Sex Transm Infect. 2003; 79(2): 163-165, doi: 10.1136/ sti.79.2.163, indexed in Pubmed: 12690144. 
19. Korzeniewski K. Peacekeeping in South-East Asia. IJHS. 2008; 1(3): 88-92

20. Korzeniewski K, Kierznikowicz B, Olszański R. Sexually transmitted diseases among Polish soldiers serving in the U.N. peace missions in Lebanon and Cambodia. Int Marit Health. 2003; 54(1-4): 101-107, indexed in Pubmed: 14974783.

21. Hyams KC, Hanson K, Wignall FS, et al. The impact of infectious diseases on the health of U.S. troops deployed to the Persian Gulf during operations Desert Shield and Desert Storm. Clin Infect Dis. 1995; 20(6): 1497-1504, doi: 10.1093/clinids/20.6.1497, indexed in Pubmed: 7548499.

22. Zenilman JM, Glass G, Shields T, et al. Geographic epidemiology of gonorrhoea and chlamydia on a large military installation: application of a GIS system. Sex Transm Infect. 2002; 78(1): 40-44, doi: 10.1136/sti.78.1.40, indexed in Pubmed: 11872858.

23. Cecil JA, Howell MR, Tawes JJ, et al. Features of Chlamydia trachomatis and Neisseria gonorrhoeae infection in male Army recruits. J Infect Dis. 2001; 184(9): 1216-1219, doi: 10.1086/323662, indexed in Pubmed: 11598849.

24. Aldous WK, Robertson JL, Robinson BJ, et al. Rates of gonorrhea and Chlamydia in U.S. military personnel deployed to Iraq and Afghanistan (2004-2009). Mil Med. 2011; 176(6): 705-710, doi: 10.7205/milmed-d-10-00218, indexed in Pubmed: 21702394.

25. USACHPPM. A Guide to Female Soldier Readiness. USACHPPM Technical Guide 281. U.S. Army Center for Health Promotion \& Preventive Medicine. January 2007. http://chppm-www.apgea. army.mil/documents/TG/TECHGUID/TG281 January2007-1.pdf.

26. Rossi KR, Nowak G. Assessing the Burden of Chlamydia and Gonorrhea for Deployed and Active Duty Personnel Assigned Outside the USA. Mil Med. 2019; 184(Suppl 1): 21-27, doi: 10.1093/milmed/ usy366, indexed in Pubmed: 30901398.

27. Ahmadi MH, Mirsalehian A, Bahador A. Association of Chlamydia trachomatis with infertility and clinical manifestations: a systematic review and meta-analysis of case-control studies. Infect Dis (Lond). 2016; 48(7): 517-523, doi: 10.3109/23744235.2016.1160421, indexed in Pubmed: 27064452.

28. Niebuhr DW, Tobler SK, Jordan NN, Singer DE. Sexually transmitted infections among military recruits. In: DeKoning BL (Ed.). Recruit Medicine. Borden Institute Walter Reed Army Medical Center, Office of the Surgeon General at TMM Publications, Washington DC 2006: 255-275.

29. Jordan NN, Lee Se, Nowak G, et al. Chlamydia trachomatis reported among U.S. active duty service members, 2000-2008. Mil Med. 2011; 176(3): 312-319, doi: 10.7205/milmed-d-10-00212, indexed in Pubmed: 21456359.

30. Brown A, Brundage J, Tomlinson J, et al. The U.S. Army HIV Testing Program: The First Decade. Mil Med. 1996; 161(2): 117-122, doi: 10.1093/milmed/161.2.117.

31. Vu MQ, Steketee RW, Valleroy L, et al. HIV incidence in the United States, 1978-1999. J Acquir Immune Defic Syndr. 2002; 31(2): 188-201, doi: 10.1097/00126334-200210010-00010, indexed in Pubmed: 12394798.

32. Renzullo PO, Sateren WB, Garner RP, et al. HIV-1 seroconversion in United States Army active duty personnel, 1985-1999. AIDS. 2001; 15(12): 1569-1574, doi: 10.1097/00002030-200108170-00015, indexed in Pubmed: 11504990.

33. Armed Forces Health Surveillance Branch. Sexually transmitted infections, active component, U.S. Armed Forces, 2011-2019. MSMIR. 2020; 27(3): 2-11, indexed in Pubmed: 32228001.
34. Wright J, Albright TS, Gehrich AP, et al. Sexually transmitted diseases in Operation Iraqi Freedom/Operation Enduring Freedom. Mil Med. 2006; 171(10): 1024-1026, doi: 10.7205/milmed.171.10.1024, indexed in Pubmed: 17076459.

35. Shafer MA, Boyer CB, Shaffer RA, et al. Correlates of sexually transmitted diseases in a young male deployed military operation. Mil Med. 2002; 167(6): 496-500, indexed in Pubmed: 12099086.

36. Gaydos CA, Howell MR, Quinn TC, et al. Sustained high prevalence of Chlamydia trachomatis infections in female army recruits. Sex Transm Dis. 2003; 30(7): 539-544, doi: 10.1097/00007435200307000-00002, indexed in Pubmed: 12838080.

37. Weinstock H, Berman S, Cates W. Sexually transmitted diseases among American youth: incidence and prevalence estimates, 2000. Perspectives on Sexual and Reproductive Health. 2004; 36(1): 6-10, doi: 10.1363/3600604.

38. Deiss R, Bower R, Co E, et al. The association between sexually transmitted infections, length of service and other demographic factors in the U.S. Military. PLoS One. 2016; 11(12): e0167892, doi: 10.1371/journal.pone.0167892.

39. Shafer MAB, Boyer CB, Pollack LM, et al. Acquisition of Chlamydia trachomatis by young women during their first year of military service. Sex Transm Dis. 2008; 35(3): 255-259, doi: 10.1097/ OLQ.0b013e31815c1bd0, indexed in Pubmed: 18490868.

40. Centers for Disease Control and Prevention. Sexually Transmitted Disease Surveillance 2018. National Surveillance Data for Chlamydia, Gonorrhea, and Syphilis. October 2019. http://www.cdc. gov/std/stats.

41. Berg SW. Sexually Transmitted Diseases and Human Immunodeficiency Virus Infection. In: Kelley PW. (Ed). Military Preventive Medicine: Mobilization and Deployment. Vol. 2. Borden Institute Walter Reed Army Medical Center, Office of the Surgeon General at TMM Publications, Washington DC 2005: 1146-1175.

42. Coutinho RA. Epidemiology of sexually transmitted diseases. Sex Transm Dis. 1994; 21(2 Suppl): S51-S52, indexed in Pubmed: 8042116.

43. Gottwald C, Schwarz NG, Frickmann H. Sexually Transmitted Infections in Soldiers - A Cross-Sectional Assessment in German Paratroopers and Navy Soldiers and a Literature Review. Eur J Microbiol Immunol (Bp). 2019; 9(4): 138-143, doi: 10.1556/1886.2019.00023, indexed in Pubmed: 31934366.

44. Aral So, Holmes KK. Epidemiology of sexual behaviour and sexually transmitted diseases. In: Holmes KK, Mardh PA, Sparling PF, Wiesner PJ. (Ed). Sexually Transmitted Diseases. McGraw-Hill, New York 1990: 19-36.

45. Harbertson J, Scott PT, Lemus H, et al. Cross-Sectional Study of Sexual Behavior, Alcohol Use, and Mental Health Conditions Associated With Sexually Transmitted Infections Among Deploying Shipboard US Military Personnel. Mil Med. 2019; 184(11-12): e693-e700, doi: 10.1093/milmed/usz070, indexed in Pubmed: 31004170.

46. Hart G. Psychological aspects of venereal disease in a war environment. Soc Sci Med. 1973; 7(6): 455-467, doi: 10.1016/00377856(73)90012-7, indexed in Pubmed: 4740606.

47. Hooper RR, Reynolds GH, Jones OG, et al. Cohort study of venereal disease. I: the risk of gonorrhea transmission from infected women to men. Am J Epidemiol. 1978; 108(2): 136-144, doi: 10.1093/ oxfordjournals.aje.a112597, indexed in Pubmed: 707474.

48. Korzeniewski K. Urogenital Chlamydia trachomatis in the environment of soldiers from the Polish Special Forces. Ann Agric Environ Med. 2019; 26(1): 51-54, doi: 10.26444/aaem/85591, indexed in Pubmed: 30922029. 